\title{
"Un arcoíris en medio de la tempestad". Visiones del potrero cubano en el siglo XIX
}

\author{
Funes Monzote, Reinaldo \\ "Un arcoíris en medio de la tempestad". Visiones del potrero cubano en el siglo XIX \\ Mundo Agrario, vol. 21, núm. 46, 2020 \\ Universidad Nacional de La Plata, Argentina \\ Disponible en: http://www.redalyc.org/articulo.oa?id=84562590006 \\ DOI: https://doi.org/10.24215/15155994e133
}

Esta obra está bajo una Licencia Creative Commons Atribución-NoComercial-Compartirlgual 4.0 Internacional. 
Dossier: Ganadería en el mundo americano: algunas reflexiones sobre tecnología, consumo e intercambio

\title{
"Un arcoíris en medio de la tempestad". Visiones del potrero cubano en el siglo XIX
}

\author{
"A rainbow in the middle of a tempest". Visions of the Cuban "potrero" during the XIX century \\ Reinaldo Funes Monzote \\ Universidad de La Habana, Cuba \\ DOI: https://doi.org/10.24215/15155994e133 \\ Redalyc: http://www.redalyc.org/articulo.oa?id=84562590006
}

Yale University, Estados Unidos

rfunesmonzote@gmail.com

Recepción: 17 Septiembre 2019

Aprobación: 19 Diciembre 2019

\begin{abstract}
Resumen:
La historiografía agraria sobre Cuba en el siglo XIX ha puesto el foco en el azúcar, por la gran transformación económica, social y ambiental que convirtió a la isla en el primer exportador mundial. Sin embargo, muy poco se conoce sobre la evolución de la ganadería en el mismo siglo. Este trabajo ofrece elementos generales de la expansión del potrero y sus características en las zonas plantacionistas y aquellas aún dominadas por la actividad ganadera. El trabajo utiliza la estadística general existente y a los autores que se ocuparon del tema, para dar una visión sobre la importancia, limitaciones y obstáculos de esta nueva ganadería en la transición hacia un modelo agrario dominado por la agroindustria azucarera.
\end{abstract}

Palabras ClaVe: Ganadería, Potreros, Haciendas, Plantación esclavista, Azúcar, Siglo XIX, Cuba.

\section{Abstract:}

The agrarian historiography about XIX century Cuba has focused on sugar, due to the great economic, social and environmental transformation after escalating to the first place as an exporter to the international market. However, very few researches exist about livestock farming and its changes during the same century. This work offers some general elements of the extension of "potreros" or pens, on the Cuban landscape and its different characteristics on the plantation areas and those still dominated by the cattle ranches. We use general statistics available and authors who wrote about agriculture and livestock in that context, to discuss the relevance, limitations, and obstacles of this new form of animal husbandry in the middle of a transition to an agricultural model dominated by the sugar agroindustry.

KEYWORDS: Livestock, Cattle ranch, Pens, Slavery plantations, Sugar, XIX century, Cuba.

\section{INTRODUCCIÓN}

En 1964 el historiador Manuel Moreno Fraginals publicó por vez primera su obra ya clásica El Ingenio: Complejo económico social cubano del azúcar, más tarde ampliada a tres volúmenes (1978). Como toda gran obra, su influencia proyectó una larga sombra sobre los autores de su generación y las siguientes. Sus tesis fueron enriquecidas, discutidas o superadas por estudios que le sucedieron y que amplían el conocimiento de la economía y la sociedad cubana ligada al auge de la plantación esclavista azucarera en el siglo XIX. (Piqueras, 1999) Esa condición de "cash crop" fue compartida de lejos por el tabaco y durante menos tiempo por el café (Ortiz, 1940; Rivero, 1964; Stubbs, 1985; López, 2015; Pérez de la Riva, 1944).

Sin embargo, en todas las épocas la ocupación azucarera del espacio cubano estuvo mayormente compartida, fue precedida o sería reemplazada por la ganadería vacuna, actividad que casi siempre abarcó mayor extensión territorial. La falta de estudios sobre esta es en parte consecuencia de la prioridad dada al azúcar en la investigación histórica de la agricultura cubana. Sin bien existen algunos trabajos pioneros acerca de diferentes etapas de la evolución ganadera, no pasan de ser avances parciales que dejan muchas lagunas (Marrero, 1984; Balboa, 1991; González, 2008; Funes, 2008, 2012a, 2012b). La carencia de estudios sobre la ganadería no es solo una característica de la historiografía cubana, sino que es algo que se repite en casi 
toda la historia agraria latinoamericana y caribeña, salvo en aquellos países y regiones donde la ganadería fue el principal producto de exportación a las metrópolis y mercados internacionales (Sábato, 1981; Edelman, 1992; Slatta, 1997; Bell, 1998; Amaral, 1998; Sesto, 2005; Wilcox, 2017; Van Ausdal y Wilcox, 2018).

El presente texto se dedica a explorar una de las fases fundamentales de la transformación histórica de la ganadería en Cuba: la transición desde las haciendas ganaderas originales denominadas hatos y corrales hacia la generalización de los potreros a lo largo del siglo XIX, como una nueva unidad de menos extensión y más especializada. Este proceso no se podría entender sin tomar en cuenta la expansión de la economía de plantaciones y su influencia sobre las estructuras agrarias tradicionales y la intensificación de la agricultura tropical bajo el influjo de la nueva era industrial (Funes, 2012a). En comparación con otros estudios sobre el tema ganadero en el contexto Latinoamericano y caribeño, se puede decir que el potrero cubano fue tardío respecto al caso de Jamaica (Higman, 1989; Shepherd, 1991, 2009; Morgan, 1995), pero anterior a la difusión de esas unidades en otras regiones continentales del Caribe, como ocurrió con los potreros colombianos desde la década de 1850 (Molano, 1992; Van Ausdal, 2009).

De acuerdo con el Diccionario de la Real Academia Española de la Lengua, la palabra potrero tiene varios significados: 1, sitio destinado a la cría y pasto de ganado, de uso más general y en España; ${ }^{1}$ 2, terreno cercado con pastos para alimentar y guardar el ganado, de uso americano, y 3, terreno inculto y sin edificar, donde suelen jugar los muchachos, más común en países como Argentina, Bolivia, Colombia y Perú. Es a la segunda de esas acepciones a las que se hace referencia aquí, pero sin excluir del todo la idea de un terreno abandonado con poca atención y de bajo rendimiento en la crianza animal. En su etapa inicial en Cuba estuvieron presentes ambas connotaciones, aunque el empleo de la palabra fue positivo en comparación con las extensas haciendas ganaderas que le precedieron.

Hacia la segunda mitad del siglo XIX los potreros constituían la unidad agraria que mayor extensión ocupaba en la geografía cubana. La dedicación fundamental del potrero era la cría de ganado vacuno, equino y porcino, aunque muchas veces esta actividad se combinaba con la siembra de cultivos para el autoconsumo o la comercialización en los mercados locales. De acuerdo con el diccionario de Esteban Pichardo (1862 [1836], p. 216), se trataba de "una hacienda de campo de más o menos extensión de terreno cercado, limpio y destinado al pasto, cría y ceba de toda especie de Ganado". En un artículo de 1841 de las Memorias de la Sociedad Económica de La Habana se le caracterizaba como "un espacio de tierra más o menos grande cercado con la idea de criar ganados, para cuyo efecto tiene los establecimientos necesarios”. En ese sentido, se expresaba que los había de 40 caballerías ( 1 caballería $=13,4$ h) o más, y otros de solo dos caballerías. ${ }^{2}$

La diversidad sería uno de los rasgos fundamentales del potrero, palabra que no solo identifica al conjunto de la finca ganadera sino también a sus propias subdivisiones interiores. El abogado y hacendado ganadero de Puerto Príncipe, Manuel Monteverde (1854, pp. 44-45), ofreció una de las definiciones más completas. A su juicio, la aplicación primitiva del término fue la de un terreno cercado para recoger y criar los potros. Pero en el momento que escribía, el nombre identificaba a las fincas dedicadas a la ceba de ganado vacuno, aunque muchos criaban también caballos, cerdos y ovejas. Indicó además que solían fomentarse en terrenos de buena calidad y cubiertos de bosque, con pastos que crecían espontáneos tras los desmontes o con pastos cultivados como la yerba de guinea (Panicum maximun), el millo (Roig,1965, t. 2, pp. 681-682) ${ }^{3}$ y la yerba de Brasil o de Pará (Panicum purpurascens) Igualmente resalta aspectos como la distancia óptima al mercado, requerimientos de mano de obra y cantidad de animales más adecuada de acuerdo con el terreno disponible (Monteverde, 1856, pp. 44-45).

Por la misma época el geógrafo José María de la Torre (1854, p. 61) definió el potrero como una hacienda cercada, de menos extensión de terreno que los hatos y corrales, pero de pastos más abundantes, dedicados a la ceba de reses vacunas y cría caballar. El número de animales estaba en dependencia de la proporción entre áreas de sabanas y de montes. A mayor extensión de las primeras se podría criar más cantidad de ganado y viceversa. De estar bien asistidos, consideraba que podían cebar por término medio en cada caballería hasta 
25 cabezas de vacuno. No obstante, otros autores como Monteverde (1856, p. 48) estimaron más realista la proporción de 12 a 16 cabezas por caballería.

La rápida expansión del potrero en el siglo XIX fue paralela a la transformación de las estructuras agrarias bajo el impulso de la economía de plantaciones. Si al inicio irrumpió de forma lenta en la cercanía de los principales núcleos de población, en la zona destinada a las estancias, con el tiempo se convirtió en una de las fincas más características tras el proceso la demolición de las haciendas originales. Asimismo, pasó a ser la unidad predominante en las tierras abandonadas por los ingenios azucareros y otras plantaciones. Un dato significativo es que en el censo de 1862 apareció como la segunda actividad económica en cantidad de esclavos, solo superada por los ingenios, lo que invita a estudios futuros sobre las relaciones entre ganadería y esclavitud en el contexto cubano. (Noticias estadísticas, 1864) ${ }^{4}$

A pesar de la enorme extensión territorial que llegó a ocupar y de su importancia en la economía insular, se conoce poco sobre la forma en que surgieron y luego se multiplicaron los potreros en la geografía insular. Desde luego, fue este un proceso paulatino. Como bien afirmaban muchos de los estudiosos del siglo XIX a los que haremos referencia, la ganadería en los potreros aún mantuvo buena parte de las características del sistema extensivo de crianza libre. Pero, a su vez, no se pueden desconocer los múltiples cambios económicos, sociales y técnicos ocurridos a partir de su proliferación. Este primer acercamiento al tema estará basado fundamentalmente en las visiones de los autores contemporáneos que escribieron sobre ganadería en general y sobre los llamados potreros en particular.

\section{Ganaderos en tierras de pasto labrado}

La aparición del potrero como unidad agraria en Cuba se vincula al inicio de la subdivisión de los hatos y corrales en la zona habanera, así como a la demolición de los primeros ingenios azucareros. Le Riverend (1992, p. 211) estima que fue consecuencia de una incipiente especialización en un uso más intensivo de los pastos naturales para la ceba y engorde del ganado que iba destinado al mercado de la ciudad. En su opinión, esa tendencia no se encontraba claramente definida antes de 1760, pero sí existían antes de esa fecha algunos de sus elementos "germinativos". Asimismo, destaca una intensificación de ese proceso a partir de que se amplió el mercado de la carne con la presencia de mayor concentración de tropas españolas en la villa a partir de 1770.

En el padrón de la isla de Cuba, realizado en 1775 bajo el gobierno del capitán general marqués de la Torre, aparecían ya 339 potreros, además de 982 hatos y 617 corrales. Se le definía como una unidad destinada a la cría de ganado sin medida precisa, pero cercada y de buenos pastos para cebar y engordar el ganado. Confirmación de esa tendencia fue el bando dictado por el propio de la Torre, el 11 de marzo de 1776, con el fin de que las estancias y sitios de labor no se convirtieran en potreros de ceba sin licencia del gobernador y capitán general. ${ }^{5}$ El mismo se refería a esa transformación como un "pernicioso abuso", que provocaba el abandono de la agricultura, sin detenerse a considerar "el perjuicio que resulta al público con la falta de los frutos de primera necesidad, como es la yuca, de que se fabrica el pan provincial, los granos, huevos, aves y demás miniestras". Entre las medidas adoptadas, se prohibió formar nuevos potreros para la ceba de ganados en un radio de 10 leguas de distancia $(45 \mathrm{~km})$. Los ya existentes en esa área tendrían la obligación de afianzar los cercados en un plazo de cuatro meses, bien con piedras o con árboles, y los ingenios debían mantener sus potreros cercados para el pasto de las boyadas. En caso de que los dueños de potreros quisieran arrendarlos, se daría preferencia a quienes se propusieran dedicarlos a los cultivos.

El 1783 el regidor Baltasar de Sotolongo, en su dictamen al cabildo habanero a propósito de un expediente sobre el abasto de carne en la ciudad, se refería a la diferencia con el tipo de ganadería que se practicaba en España y México. ${ }^{6}$ Mientras en la metrópoli se criaban las reses por medio del pastoreo o el forraje, en el segundo la abundancia de ganados permitía su aumento aun sin cebarse en "territorios labrados", y no solo abastecía a sus moradores, sino que le sobraba "para traer a esta isla”. En Cuba, por el contrario, no existía 
más cultivo que el procedente de las quemas una vez al año. La falta de buenos pastos era para Sotolongo un factor determinante en la crisis de la ganadería. Elogió por tanto la aparición de potreros en zonas próximas a la ciudad en los anteriores 25 años, aunque aún no eran "suficientes para recibir la proporción de ganados que necesiten este aumento en las presentes circunstancias".

Muchos de esos potreros se habían establecido "en territorios que por cansados o pedregosos" no eran ya "tan útiles a la labor de granos y vituallas". Sin embargo, sí lo eran para potreros, único medio a su juicio para obtener un mayor rendimiento en carne. En apoyo a esta idea citó estimaciones de que una res cebada en potreros llegaba a 15 arrobas (375 libras), mientras que en las haciendas no solían rebasar las 5 arrobas (125 libras); también expuso que un potrero de 100 caballerías producía más carne en un año que un hato con sus más de 1.400 caballerías.

En los largos conflictos entre la Marina Real y los hacendados azucareros por el dominio y explotación de los bosques cubanos entre fines del siglo XVIII e inicios del siglo XIX apareció varias veces el tema de la ganadería (Funes, 2008). La primera utilizó el argumento de la crisis de esta actividad como consecuencia del rápido ritmo de demolición de las haciendas durante la coyuntura alcista tras la revolución en Haití. El Director de los Cortes del Rey, ${ }^{7}$ Pedro Acevedo, sacó el tema a relucir en una de las sesiones de la Junta de Maderas de La Habana de 1797, pues preveía una mayor decadencia del ramo, porque "no se verifica el fin de ocuparse y labrar las tierras demolidas por colonos que en sus pequeñas labranzas equivalgan o superen las dotaciones de las respectivas haciendas". ${ }^{8}$ Para establecer sus cálculos, partía de una extensión ideal de 10 caballerías por cada potrero, 33 caballerías por ingenio y 5 caballerías por estancia.

Los vocales de la Junta de Maderas acordaron pedir un informe al Ayuntamiento, que mostró una imagen menos pesimista. Aunque al final de la crianza en una hacienda demolida no lo siguieran de inmediato "las pequeñas crianzas que equivalgan o superen las dotaciones", los comisarios señalaron que los sitios y estancias suplirían esa falta con ventaja. Un factor era la introducción de cerdos de "nuevas castas", como la llamada gallega, pues cada ejemplar equivalía a tres de los criollos. En reunión anterior del Cabildo, el regidor José Armenteros había presentado un detallado informe donde afirmaba que las demoliciones contribuían al aumento y la mejora en el abastecimiento de carne y la agricultura en general. Y para demostrarlo puso el siguiente ejemplo de la demolición de hato Bainoa:

compuesto de 16 leguas planas, está repartido en potreros y sitios de labor, uno de aquellos es de Don Domingo de la Parra, ceba más de mil novillos cada año, y tiene numerosa crianza; otro del coronel conde de Zaldívar, ceba casi lo mismo, cría tanto ganado mayor y menor que en breve igualará, sino excediere, a la dotación que gozaba el hato; y otro del mismo Regidor (...) Armenteros, que también ceba, mantiene sus boyadas, y anualmente cría 35 o más terneros, fuera de porción de cerdos; omitiendo mencionar otros potreros, sitios de labor y hasta un ingenio establecidos dentro de las referidas 16 leguas, porque basta y sobra la expresión hecha a convencer lo propuesto. Que una res cebada, y aún la nacida en pasto labrado, vale más que dos de las que se crían en Hatos por su rendimiento y condición, de que proviene también el que se multiplique el número de todo ganado.

(AGI, Ultramar, 9/7,2. Expediente del Real Consulado sobre que se reforme el reglamento de maderas... en aquella Isla por los perjuicios que dice ocasiona a la agricultura y al comercio. La Habana, mayo 22 de 1798)

Francisco de Arango y Parreño (2006 [1807]) elogió la aparición de los potreros en su "Informe sobre la abolición de la pesa". En ese sentido, diferenció los "tiempos primitivos", cuando "todos nuestros bienes consistían principalmente (...) en desiertos destinados a la crianza silvestre de cerdos y ganado", de los tiempos posteriores de incremento de la agricultura y el lujo, cuando se introdujo el gusto de comer carne cebada de puerco y vacuno. De esa manera surgió "otra clase de ganaderos en tierras de pasto labrado", quienes por la excelencia de sus carnes se hicieron en pocos años "dueños de todo consumo", con excepción de los militares abastecidos todavía por el sistema de la pesa. Según Arango (2006, pp. 6-8), los conocedores fijaban hacia 1760 la época en que comenzaron esos cambios. Más adelante, se multiplicaron los potreros "felizmente" por todas partes "en términos asombrosos" y se encargaron de suministrar a la agricultura los bueyes, además de "proveer a la gente rica y a las familias menos acomodadas". A pesar de esta imagen optimista, a fines del siglo 
XVIII la extensión de los potreros era aún limitada. El funcionario de la administración colonial José Pablo Valiente escribió en 1797:

en los contornos de La Habana se aplican a ella (a la cría de ganados) pedazos de tierra desmontados, cercados y mucho más reducidos; y esta especie de pequeñas dehesas, que se llaman potreros, no forman objeto en comparación de los hatos y corrales para lo que es ocupación de terreno. (Zamora, 1840, pp., 48-49) 9

Años más tarde Miguel de Escalada (1851, p. 315), residente en un poblado rural de La Habana nombrado Bainoa, rememoraba los cambios desencadenados a fines del siglo XVIII. Por una parte, refirió que, debido a trabas en el cultivo del tabaco, muchos vegueros abandonaron esa actividad desde 1788 para dedicar sus terrenos a la formación de potreros. De esa forma, a una superficie "adornada de hermosas vegas salpicadas de solícitos vegueros" la sustituyó otra "matizada de toda clase de ganado mayor y menor". Por otra parte, ese proceso recibió gran impulso durante el gobierno del capitán general Luis de las Casas (1790-1796), quien favoreció la cría de cerdos gallegos, luego llamados criollos. Esa circunstancia estimuló el cultivo de granos para la ceba del ganado y así "los potreros de Bainoa aumentaron y alargaron sus conucos, que en primavera y otoño se sellaban de maíz amarillo con semillas de Galicia y Asturias” (Escalada, 1858, p. 200).

Escalada (1851, p. 314) describió asimismo los cambios en el abastecimiento de carne al mercado de La Habana. Al respecto, evocaba épocas pasadas en que prevalecía el sistema de la pesa para el abasto y "la buena hospitalidad y armonía" con los criadores de Bayamo y Puerto Príncipe cuando conducían sus ganados a La Habana, donde los dueños de potreros no cobraban "corral o piso al criador transeúnte, porque se hubiera considerado como una infracción de los deberes de buen vecino”. Existía entonces una relación más directa entre los criadores y el mercado, que con el tiempo fue modificada tanto por la proliferación de los potreros de ceba como la de intermediarios y revendedores. De acuerdo con Escalada (1851, p. 316), los nuevos cebadores "interceptaban los ganados que bajaban de tierra adentro para las carnicerías de La Habana". A la vez, se dirigían a la parte oriental para adquirir nuevos toros y novillos, mientras que las reses se negociaban al contado, incluyendo las compras que se hacían en los territorios de Bainoa o de la jurisdicción de Güines.

Los cuestionamientos sobre la incidencia de las subdivisiones de las haciendas ganaderas tradicionales en el estado de la cría de ganado y el abasto de carne a las poblaciones continuaron en el siglo XIX. El potrero fue la esperanza de un nuevo tipo de ganadería más productiva, pero las expectativas más optimistas no se cumplieron. Aunque las estadísticas de los censos se deben tomar con cautela, por sus presumibles o comprobados errores, al menos permiten observar una tendencia al crecimiento demográfico por encima del aumento de la cantidad de ganado vacuno y porcino. Según el censo de 1827 la masa bovina era superior en unas 400 mil cabezas respecto al total de habitantes en la isla, en cambio el censo de 1862 mostró una relación inversa de alrededor de 140 mil habitantes por encima de las existencias de ganado vacuno. En el mismo período la población cubana llegó casi a duplicarse, de poco más de 700 mil a cerca de 1.380.000 habitantes.

\section{MÁs ALLÁ DE LA Frontera HABANERA: EXPANSIÓN DE LOS POTREROS}

A lo largo del siglo XIX, la trayectoria de la ganadería cubana fue muy distinta a la de los opulentos ingenios semimecanizados o mecanizados concentrados en el occidente de Cuba. Los criadores de ganado debieron enfrentar diversos obstáculos, que limitaron la posibilidad de ampliar la oferta interna de fuerza de tracción y alimentos. Por un lado, se debe destacar la incidencia de las nuevas tecnologías de la era del vapor, tanto las máquinas instaladas en los ingenios para la elaboración del azúcar como los ferrocarriles, que motivaron el reemplazo de gran número de bueyes y équidos. Por otro lado, la significativa importación de productos extranjeros de origen animal representó una dura competencia para los ganaderos (Sluyter, 2012, pp. 169-210). Como consecuencia de ello, mientras la agricultura plantacionista alcanzaba gran esplendor, la ganadería se vería sumida en una larga decadencia, que no escapó al escrutinio de los contemporáneos (Funes, 2012a). 
Con independencia de dicha crisis del sector ganadero, a lo largo del siglo XIX se produjo el proceso de expansión de los potreros como parte del reemplazo de los sistemas de crianza libre en hatos y corrales (o haciendas principales). En muchas regiones de la isla los potreros pasaron a ser el elemento predominante de los paisajes rurales. Debido a la mayor demanda de caña en los nuevos ingenios semimecanizados o mecanizados, muchas áreas dedicadas antes al mantenimiento de los animales en las plantaciones fueron convertidas en cañaverales. De forma paralela, se crearon potreros más especializados tanto para la recuperación de las boyadas tras las cosechas como para brindar servicios de trasporte o de alimentación.

El paulatino abandono por los intereses azucareros de las zonas plantacionistas pioneras influyó también en la multiplicación de los potreros. El censo de 1792 recogió un total de 567 para el departamento occidental, por entonces el $97 \%$. La mayoría se localizaba en las áreas cercanas a la villa habanera. En cambio, existían solo 30 potreros en el departamento central (mitad en Trinidad y Villa Clara) y dos en el oriental (Bayamo). Por ejemplo, Novoa (2008, p. 71) señala que el primer potrero en la zona de Holguín data de 1812. Ya en el censo de 1827 el panorama era diferente. Mientras en el occidente el número fue poco más del doble, con 1.238 potreros, en el centro subieron a 1.672 y en el oriente a 188 . La tendencia se mantuvo en los censos de 1846 y 1862 (ver Tabla 1).

TABLA 1.

Fincas clasificadas como potreros entre los censos de 1792 y 1862

\begin{tabular}{|l|l|l|l|l|}
\hline Zona & $\mathbf{1 7 9 2}$ & $\mathbf{1 8 2 7}$ & $\mathbf{1 8 4 6}$ & $\mathbf{1 8 6 2}$ \\
\hline Occidente & 567 & 1.238 & 1.467 & 2.119 \\
\hline Centro & 30 & 1.672 & 2.579 & 3.608 \\
\hline Oriente & 2 & 188 & 342 & 448 \\
\hline Totales & 599 & 3.098 & 4.388 & 6.175 \\
\hline
\end{tabular}

Fuentes: "Padrón general de los habitadores de la isla de Cuba, formado en el mes de diciembre de 1792, de orden de Luis de las Casas... expresándose el número de los templos, hospitales, colegios y haciendas de campo", Memorias de la Sociedad Económica de La Habana, t. 32, p. 197. 1846. Cuadro estadístico de la Siempre fiel Isla de Cuba, correspondiente al año de 1827, Arazoza y Soler, La Habana, 1829; Cuadro Estadístico de la Siempre Fiel isla de Cuba, correspondiente al año de 1846, Imp. del Gobierno y Capitanía General, La Habana, 1847; Noticias estadisticas de la Isla de Cuba en 1862... . Imp. del Gobierno, Capitanía General y Real Hacienda, La Habana, 1864.

Nota: en el censo de 1862 solo existían dos departamentos, occidental y oriental. La denominación de zona

representa espacios aproximados a partir de delimitaciones jurisdiccionales, a fin de establecer la comparación.

A lo largo del siglo XIX el ritmo de formación de potreros de cría y ceba fue superior en la porción central de la isla, desde la zona de frontera con las plantaciones esclavistas de la llanura de Colón hasta la jurisdicción de Puerto Príncipe. En cambio, los potreros de la mitad occidental quedaron en una posición secundaria dentro de una estructura agraria dominada por la producción azucarera, como lo demuestra el peso de los bueyes dentro de la masa bovina. Se conformó así una suerte de especialización regional, por la que los potreros centroorientales enviaban los animales por tierra hacia el occidente, bien para abastecer a las zonas de plantación en su necesidad de bueyes o para el engorde final en potreros destinados a abastecer los mataderos de la capital.

Los potreros representaron la tendencia predominante, pero no llegaron a reemplazar del todo formas de crianza libre remanentes en la mitad centrooriental. Así lo demuestra la unidad agraria denominada sitio de crianza, casi inexistente en el departamento occidental. En 1827 se registraron en el departamento central 3.469 sitios de crianza y en el oriental 2.507, mientras que en 1846 fueron 1.726 y 2.496 respectivamente. Aunque debió ser una unidad muy diversa, estos sitios de crianza formaban parte de las antiguas haciendas sin deslindar, designadas como haciendas comuneras, expresión de los "pesos de posesión" de sus ocupantes (Balboa, 2013). 
En una estadística de $1877,{ }^{10}$ con la nueva subdivisión administrativa de la colonia en seis provincias, solo quedaba entre las distintas denominaciones dadas a las unidades ganaderas la de potrero ( 3.172 en toda la isla). La provincia con mayor cantidad de potreros entonces fue La Habana, con 1.078, y le seguían las de Pinar del Río (698), Santa Clara (658) y Matanzas (578). El hecho de que estos datos fueran recogidos en la etapa final de la Guerra de los Diez Años (1868-1878) determinó que solo aparecieran 72 en la provincia de Puerto Príncipe y 88 en la de Santiago de Cuba, principales escenarios de la contienda.

La expansión de los potreros durante el siglo XIX se correlaciona con el incremento de las zonas de prados o pastos naturales o artificiales. No existen estadísticas para toda la centuria, pero los censos de 1846 y 1862 muestran un cambio notable en tres lustros. Los territorios identificados como pastos naturales pasaron de 99.611 a 174.947 caballerías, y los identificados como pastos artificiales, de 17.403 a 38.608 caballerías. Aunque no se debe obviar la disparidad en la recogida de datos entre ambos censos, se puede inferir que una parte de ese incremento tuvo que ver con la sustitución por pastizales de tierras abandonadas por el azúcar. Otra buena parte de los denominados prados artificiales se debía a la apertura de potreros o sitios de crianza en medio de la floresta.

En sentido general se puede apreciar la coincidencia entre las áreas con más potreros y las de mayor extensión de pastos naturales y artificiales. En el censo de 1862 la zona del centro de la isla concentraba con diferencia la mayor área de pastos artificiales, con cerca de 22 mil caballerías en esa categoría. Se destacaban las jurisdicciones de Cienfuegos (6.548), Puerto Príncipe (5.478) y Sancti Spíritus (4.844). Otras dos jurisdicciones con una alta proporción de pastos cultivados eran Holguín (3.294) y Pinar del Río (3.960). En cuanto a los prados naturales, también fueron las jurisdicciones del centro las que ocupaban los primeros lugares, como Puerto Príncipe (37.960), Cienfuegos (25.302), Sancti Spiritus (10.858) y Santa Clara (8.419). Fuera de esa zona sobresalían Holguín (11.724) y San Cristóbal (11.530). Todos estos territorios integraban la denominada por Juan Pérez de la Riva (2004 [1968]) como la Cuba ganadera o la Cuba B. Se podría hablar de una "vocación natural" en estos territorios dominados por extensas llanuras. Sin embargo, sería exagerado atribuir a dichas condiciones una supuesta ventaja comparativa o competitiva sobre otros territorios del país.

\section{VISIÓN DEL POTRERO EN LA REGIÓN PLANTACIONISTA}

El tema de los potreros fue una constante entre los autores dedicados a la reforma de la agricultura cubana y a la transformación de su ganadería, la cual presentaba un estado decadente. Esa preocupación abarcó toda la isla, aunque se pueden establecer ciertas variaciones en el discurso y en las prácticas allí donde predominaban las plantaciones esclavistas azucareras y las zonas que mantenían la ganadería como la actividad económica fundamental. Los principios generales eran los mismos, sin embargo, para los propósitos del presente texto resulta útil hacer una distinción entre ambas regiones.

De los autores radicados en La Habana, no pueden faltar los nombres de José Jacinto de Frías y Jacott (1844), su hermano Francisco de Frías y Jacott (conde de Pozos Dulces) (1849), Francisco de Paula Serrano (1847), Ramón de la Sagra (1862) y Antonio Bachiller y Morales (1846), junto a otros menos conocidos como Miguel de Escalada (1851). Sus estudios aparecieron como folletos o libros, así como en numerosos artículos dados a conocer en las páginas de las Memorias de la Sociedad Económica de La Habana o en publicaciones periódicas como El Porvenir del Carmelo (1860-1861) y El Ateneo (1868-1869).

Una coincidencia unánime fue la crítica a los sistemas tradicionales de crianza libre en los antiguos hatos y corrales. En su memoria sobre el comercio y consumo de ganados en La Habana, Escalada (1851, p. 323) recordaba que los agraciados con las mercedes de esas haciendas se limitaron a soltar en sus tierras al ganado con sus correspondientes marcas, con unos pocos monteros que recorrían apenas los puntos más fáciles. Al mantener "casi yermos terrenos dilatados, ricos y abundantes en elementos de vegetación", se criaban diez cabezas de ganado "en el espacio en que podían sostenerse mil". A ese motivo atribuyó la importación de 
tasajo, artículo indispensable para llenar las necesidades básicas cuando aumentó la población, en lugar de ser alimentada con la carne del país.

Entre los factores que incidían en la decadencia de la ganadería se señalaban el sistema de arrendamiento de las grandes haciendas, basado en la condición de entregar una cantidad fija anual y dejar al término del contrato la misma cantidad inicial de cabezas de ganado; la falta de límites precisos en las haciendas o sitios de crianza, por lo que se mezclaba el ganado de distintos propietarios; el absentismo de los dueños; los excesivos impuestos que iban desde las zonas de crianza hasta el mercado, y el escaso aprovechamiento de todos los productos que podría brindar la ganadería. De igual manera, influían las sequías o tormentas, epidemias, los frecuentes robos de ganado y ataques de perros jíbaros y los cocodrilos en las haciendas más próximas a los humedales (Frías y Jacott, 1849, pp. 6-10).

Uno de los inconvenientes que casi siempre se mencionó fue la falta de integración entre ganadería y agricultura. Francisco de Paula Serrano (1847, p. 118) indicó la necesidad de esa interrelación "porque el cultivo debe producir los pastos de mejor calidad y en mayor abundancia, y el ganado a su vez rendir al terreno el poderoso abono de su estiércol". Para esto expuso la ventaja del sistema de prados cercados y de corta extensión. Esta debía ser la primera reforma, de modo que "auxiliándose mutuamente, se mejore el número y las condiciones del ganado". Al hablar de cultivo, especifica que no se refería al existente entonces, reducido a un escaso número de plantas y que no permitía introducir "el fecundo sistema de rotaciones". Con el tiempo, el potrero debía convertirse en el sostén de la ganadería y factor indispensable para el adelanto agrícola.

De igual manera, el conde de Pozos Dulces se mostraba optimista sobre las ventajas de esa asociación como elemento imprescindible para reformar el sistema agrícola basado en el monocultivo y la destrucción acelerada de los bosques:

La naturaleza especial del gran cultivo en la isla de Cuba ha podido repugnar hasta ahora la fecunda alianza que hoy le proponemos a la ganadería, pero no se necesita estar dotado de una gran penetración para pronosticar que este será el único expediente que podrá en lo futuro salvar a nuestra agricultura de los males que se ve rodeada. Aumento y variedad de producción, creación de nuevas industrias, florecimiento de la población y de toda la riqueza pública; tales son los óptimos frutos que brinda a nuestro país la fusión de esos ramos de su economía rural que caminando cada uno por su lado se mantiene recíprocamente en un estado de comparativo atraso y abatimiento (Frías y Jacott, 1849, p. 20).

El cultivo de los pastos artificiales fue un reclamo constante de los partidarios del sistema de potreros, a diferencia de la crianza en las grandes haciendas, responsable de que los animales se vieran "expuestos a todos los accidentes de la vida salvaje”. José Jacinto de Frías afirmaba que los potreros de crianza adolecían por lo general de los mismos males que las haciendas. Pero como sus límites eran más reducidos y sus terrenos de mejor calidad, "los inconvenientes que resultan de la escasez de pastos y de la falta de vigilancia y cuidado con los animales, son, por estas causas, menos considerables y funestos". No obstante, esas unidades estaban muy lejos de alcanzar la perfección. Frecuentemente en la época de seca el ganado se deterioraba y hasta moría de inanición. Solo en las fincas menores, como sitios, vegas y estancias, la crianza de animales presentaba un aspecto más favorable. Afirma que en esos predios "las vacas son más lecheras y los cochinos se propagan admirablemente y engordan más pronto y con menos alimentos". Aún así, estimó que solo en casos aislados podía convenir la estabulación con prados artificiales, pues para las condiciones de Cuba el sistema de potreros era el más adecuado y por eso debía buscarse su perfección (Frías y Jacott, 1844, p. 75).

Los autores de la mitad occidental del país no pasaron por alto el impacto sobre la ganadería de la aplicación en los ingenios azucareras de las tecnologías del vapor y de la revolución del ferrocarril. De acuerdo con Francisco de Paula Serrano (1847, p. 120), los progresos en ese orden llevaron a que disminuyera "en gran manera el empleo de los bueyes en carretas, trapiches y otros usos, que era tan considerable como ventajoso a los criadores". Esto había provocado que el valor de una yunta de bueyes apenas llegara a la mitad del que tenía antes. Se sumaban la paulatina desaparición de los ingenios de fuerza motriz animal y la crisis de los cafetales, junto al poco uso del arado (Frías y Jacott, 1849, p 10). 
Bachiller y Morales (1846, p. 353) citó entre los factores que afectaban a la ganadería la incidencia de los intermediarios en la venta de la carne, la baja en la venta de los bueyes y en el precio de los pastos, la carestía de la sal o la competencia de productos de origen animal procedentes del extranjero. Pero, de modo especial, señalaba: "La introducción de los caminos de hierro, la de máquinas de vapor para los ingenios, ha hecho reducir a precios muy bajos las reses, como animales de tiro". Por tanto, el negocio ganadero se dirigía a considerar "como principal objeto de la crianza destinarlo al consumo como alimentos" (Bachiller, 1846, p. 347). Circunstancias que debían tenerse presentes, a su juicio, para comprender el hecho de que existieran cada vez menos potreros, y que la mayor parte de estos se dedicasen a siembras de maíz, tabaco, etc.

Los trabajos acerca de la ganadería solían ofrecer propuestas concretas para la mejora de los potreros. Como se dijo, un elemento central debía ser su carácter de fincas mixtas. Entre los posibles cultivos que podrían implementarse en los potreros se incluían los del maíz, la yuca, el tabaco, añil, plantas oleaginosas y la cría del gusano de seda. Para ese objetivo era fundamental la atención a los cercados de las fincas. Con ese fin se podían emplear piedras, cuyo costo era más alto, o bien diferentes especies vegetales o árboles vivos, como piñón, almácigo, piña ratón, tuna brava o nopal, henequén, limoneros, algarrobo, ateje, guásima, castaño de la India, mangos y palmas reales. Estas últimas representaban además una reserva adicional de alimentos y de combustible para las fincas. Por ejemplo, uno de autores mostraba el deseo de que produjeran grano y hoja en los potreros; leña en los ingenios; hoja, grano y leña en los sitios de labor; y frutales y leña en las estancias cercanas a las ciudades. ${ }^{11}$

Acerca de la importancia de las cercas vivas, escribió Francisco de Paula Serrano (1847, p. 225): "Convenimos en que es una obra dilatada y penosa la formación de tantos cercados; pero estas son las fábricas esenciales, las máquinas indispensables de los potreros". Proponía en específico un tipo de cercas formadas por arbustos de majagua y henequén, ambas plantas con importantes aplicaciones prácticas. Por otra parte, en los potreros interiores se debían dejar árboles dispersos o sembrarlos para proveer sombra y alimento adicional a los animales. Entre los preferidos estaban las palmas, guásimas y algarrobos.

Dentro de las recomendaciones para el potrero se insistió en preservar una porción de bosques primarios y la siembra de bosques artificiales. Entre los que aportaban las maderas de construcción necesarias estaban el cedro, caoba, ácana, yaba, majagua, frijolillo o roble. Otros servían para el suministro de leña o abono, pero de modo específico los más indicados para la crianza de animales eran los que tenían algún fruto comestible o los que servían para al ramoneo, como ácana, roble, ateje, guásima, mamey, caimito, encina, algarrobo, palma, naranjo, yaya, guayaba, macagua y almendro. La significación de los potreros para amortiguar el rápido avance de la deforestación, sobre todo en los ingenios, donde "todo se reduce a ceniza", fue celebrada así en 1841:

Los bosques artificiales que deben ocupar la mitad de la extensión de cada potrero parecen como el arcoíris en medio de las tempestades; las cercas también contribuirán en gran parte a precaver los funestos efectos de la devastación de los montes en esta Isla ("Agricultura. Cartilla rústica. Diálogo de un Labrador y su hijo”, Memorias de la Sociedad Económica de La Habana, 1841, 250)

Existió coincidencia en que los potreros podían representar un contrapeso a la especialización azucarera y al empleo de trabajo esclavo, así como una vía para lograr el reparto más equitativo de la riqueza. Se consideraba, además, que estos espacios eran más propicios para la actividad de los criollos o los inmigrantes procedentes de España o de países con población de origen europeo (Serrano, 1847, p. 232). Pero las expectativas de que los potreros $\mathrm{u}$ otras fincas rurales permitieran un panorama agrícola más diversificado o equilibrado, o de que la ganadería evolucionase sobre nuevas bases, quedaron incumplidas, sobre todo en las zonas dominadas por las plantaciones esclavistas azucareras. Tampoco representaron una vía para el aumento de la población libre o para la redistribución de la riqueza.

El conde de Pozos Dulces (1849, p.11) opina que, salvo por su extensión y por su acotamiento con parte del terreno despojado de monte, los potreros son "fieles trasuntos de hatos y corrales, y en ellos se reproducen la mayor parte de los inconvenientes que distinguen a estos últimos”. Si bien se podía apreciar una mejora en 
la calidad de los pastos o la atención del ganado, cuando llegaba la estación seca desaparecían por lo general sus condiciones ventajosas. Su preocupación principal se centraba en el tipo de potreros que comenzaba a remplazar a las plantaciones demolidas tras décadas en explotación. Calculaba que en los últimos doce años más de 40.000 habitantes habían emigrado a otros puntos de la isla, "abandonando un feracísimo territorio que en su mayor parte se ha convertido en pastos naturales". De esa forma, la cría de ganados reconquistaba los terrenos abandonados por las plantaciones, pero no a través de un sistema intensivo capaz de aprovechar las ventajas de la asociación con la agricultura, sino repitiendo los mismos errores prácticos de siempre (Frías y Jacott, 1849, p. 19).

En general la atención en las zonas plantacionistas se centró en mantener las boyadas todavía necesarias en el proceso productivo del azúcar. Al margen de la incidencia de la mecanización sobre la ganadería, era aún significativo el empleo de bueyes en las carretas para la transportación de la caña de azúcar hacia el batey. Según el censo de 1846 el número de bueyes en la zona occidental casi se equiparaba al de toros y vacas (172.390 de los primeros y 180.838 de los segundos). Aunque esta proporción cambia hacia 1862 , cuando los toros y vacas superan en más de cien mil cabezas a los bueyes. En casos como las jurisdicciones de Matanzas, Cárdenas y Colón, núcleo de la plantación azucarera, el número de bueyes se mantenía por encima (63.865 por 35.857)

En territorios del centro de la isla, hacia donde avanzaba la frontera azucarera, se registró un incremento de los bueyes de 20.487 en 1827 a 84.544 en 1862 . En cambio, en la misma región el número de vacas y toros sufrió pocos cambios, si bien se mantuvo como la principal área ganadera con más de la mitad de la masa vacuna en los censos del 1827 al 1862 (Tabla 2). Hay que señalar que a lo largo del siglo XIX se consolidó una especialización diferenciada de la ganadería entre las zonas de ceba más próximas a los principales mercados consumidores y las zonas de cría en territorios más distantes. Esto quiere decir que muchos de los beneficios de la actividad iban a parar igualmente a los núcleos de ceba en las cercanías de La Habana u otras ciudades que crecieron al calor de la economía de plantaciones.

TABLA 2.

Ganado vacuno para cría-ceba y para tiro-carga

\begin{tabular}{|l|r|r|l|r|r|r|}
\hline & \multicolumn{2}{|c|}{1827} & \multicolumn{2}{c|}{1846} & \multicolumn{2}{c|}{1862} \\
\cline { 2 - 7 } & $\begin{array}{l}\text { Toros y } \\
\text { vacas }\end{array}$ & \multicolumn{1}{|c|}{ Bueyes } & $\begin{array}{l}\text { Toros y } \\
\text { vacas }\end{array}$ & Bueyes & $\begin{array}{l}\text { Toros y } \\
\text { vacas }\end{array}$ & \multicolumn{1}{l|}{ Bueyes } \\
\hline Occidente & 288.127 & 111.092 & 180.838 & 172.390 & 274.288 & 142.617 \\
\hline Centro & 581.615 & 20.487 & 431.445 & 53.502 & 523.501 & 84.544 \\
\hline Oriente & 185.960 & 8.960 & 158.070 & 31.128 & 196.452 & 19.495 \\
\hline Totales & 1.055 .702 & 140.439 & 770.353 & 257.020 & 994.241 & 246.656 \\
\hline
\end{tabular}

Fuente: Ver tabla 1.

Es posible hablar de un escaso interés por parte de los intereses económicos dominantes en el occidente hacia la actividad ganadera y la mejora de los potreros en particular. Así se explica el fracaso de la introducción de nuevas razas de ganado vacuno, bajo el auspicio de la Junta de Fomento de La Habana en 1848. La misión de compra en Estados Unidos fue encomendada a José María de la Torre (1849), quien remitió a la isla ejemplares de las razas Durham, Devon y Hertford, junto a otros animales, implementos agrícolas y bibliografía. Sin embargo, tras ser entregados a pudientes hacendados de la capital, los bovinos murieron por distintas causas. De igual manera, en la región occidental fue más difícil concretar la realización de ferias ganaderas, salvo en el caso de las efectuadas en la ciudad de Colón desde 1859, otra de las vías para la reforma de la ganadería en la isla.

Se puede concluir que los textos ganaderos provenientes de la capital de la isla se movieron a un nivel más teórico que práctico. Al plantearse la búsqueda de un potrero ideal, no solían aparecer muchos ejemplos concretos o cifras basadas en experiencias de manejo. El tema de la crisis de la ganadería generó polémicas 
o posiciones encontradas en torno a algunas cuestiones como cuál resultaría la estrategia más adecuada para mejorar las razas de animales criollos (¿selección o cruzamiento?), o cuál sería la política comercial más favorable al proceso (¿librecambio o proteccionismo?). En no pocos casos, la línea divisoria tenía que ver con la defensa o no de los intereses de las zonas ganaderas frente a la posición hegemónica de la agroindustria azucarera (Ghorbal, 2006; Funes, 2012c; Cabrera, 2018). No es de extrañar entonces que los principales esfuerzos por la mejora de la ganadería fueran hechos por los hacendados del interior del país, cuyos intereses no dependían, al menos directamente, de la esplendorosa plantación esclavista.

\section{EL POTRERO VISTO DESDE LAS ZONAS GANADERAS}

Durante el siglo XIX los potreros se multiplicaron con rapidez en las regiones ganaderas del centro y oriente de la isla. Como se vio antes, la mayor presencia de este tipo de unidades y a su vez de pastos naturales o artificiales, se concentró en jurisdicciones del este como Puerto Príncipe, Sancti Spiritus, Santa Clara, Remedios, Cienfuegos, Holguín y Bayamo. Esto explica la aparición de importantes escritos sobre el tema, que ofrecían valiosa información acerca de los potreros y la ganadería en localidades que mantenían el peso de la cría de animales, en medio de la transición de los sistemas de crianza libre hacia los pastizales cercados.

El autor más prolífico en el tema fue el hacendado Manuel Monteverde (1795-1871), de origen dominicano y radicado en Puerto Príncipe desde 1822. En un estudio sobre la industria pecuaria en esa región publicado en 1856, Monteverde hizo una profunda evaluación de las causas de la crisis por la que atravesaba la actividad ganadera en su jurisdicción y otras zonas ganaderas, debido a que los beneficios no compensaban los gastos. En su análisis ofreció una comparación de la cría de ganados en las denominadas haciendas comuneras (o "crianza suelta") y la que tenía lugar en los potreros. Para el primer caso indicaba un promedio de tierras equivalentes a 500 pesos de posesión, ${ }^{12}$ en las que se criaban 500 reses vacunas, 200 cerdos y 50 equinos, además de poseer 200 colmenas. Atendida por 4 esclavos dirigidos por un mayoral, los productos anuales consistían en el nacimiento de 90 terneros (y la leche de las madres durante tres meses), 40 cerdos, 18 potros, 20 arrobas de cera y 20 botijas de miel (cada una de 25 botellas). Esto representaba 1.683 pesos anuales, mientras que los gastos en el sostenimiento de la hacienda y la manutención de trabajadores ascendían a 1.733 pesos.

Para el caso de los potreros, Monteverde toma una extensión de 30 caballerías de tierra: 25 sembradas de yerba de guinea, 2 para el batey, curación de los animales y cultivos como plátanos, cañaverales, frutas, etc., y 3 de monte para tener una reserva de maderas conque reponer las cercas, sacar bejucos y para futuras labranzas. El capital de animales estaba conformado por 400 novillos, 200 cerdos, 12 caballos, 4 yuntas de bueyes para servicio de la finca y 100 colmenas. Para su atención se destinaba un mayoral y diez esclavos (o peones). Entre los productos de la finca, con el engorde de los novillos aumentaban su valor en 8 pesos, además de la venta de 40 cerdos y 10 arrobas de cera y 10 botijas de miel. Adicionalmente se obtenían diversos bienes para la manutención de los trabajadores y el engorde de los animales durante la seca (200 serones de maíz y plátanos y otros 100 de frutas). El total de esas producciones alcanzaba al año 3.801 pesos, pero los gastos representaban 4.030 pesos, o sea, una pérdida aproximada de 229 pesos.

Monteverde (1856, p. 44) señaló que los potreros solían establecerse en un terreno de buena calidad y que podía estar en sus inicios cubierto de bosque. La distancia de los núcleos urbanos era un elemento para tener en cuenta, pues en su opinión los que se encontraban a más de 8 leguas $(36 \mathrm{~km})$ de la villa de Puerto Príncipe dejaban una menor utilidad, debido al incremento de los costos y a las dificultades que representaba la conducción del ganado al mercado. Un punto al que dedicó atención fue a la merma de los rendimientos en los sistemas de crianza tradicionales en hatos y corrales. A su juicio, en esos momentos ninguna de las haciendas originales daba "la tercera parte de lo que criaba ahora 50 años, y lo que cría es raquítico y miserable"; o sea, las dehesas "que antes criaban 1.000 reses lozanas, no les sostienen hoy 300 ruines, y en 10 años no reponen los estragos de una seca grande”. Entre las causas, mencionaba que en los 
primeros tiempos se podían aprovechar los despojos de los bosques, cuya extensión permitía que lloviera más a menudo y más copiosamente, la mayor fecundidad de las hembras y la menor degeneración sufrida por la raza introducida por los colonizadores, así como la abundancia de pastos (Monteverde, 1856, p. 39). Sin el reemplazo por los potreros de muchas de las "esterilizadas haciendas", consideraba "muy comprometida" la subsistencia de las zonas ganaderas.

Sin embargo, la formación de nuevos potreros incrementó también la deforestación en el área de las antiguas haciendas. Monteverde expone el ejemplo del hato Cahobabo, que era casi en su totalidad montuoso y que tenía una cantidad de ganados reducida para pastar en su única sabana. Pero después de que los montes fueron "reducidos a potreros" fue posible alimentar diez veces más al ganado en los nuevos pastos artificiales o los pastos naturales tras ser abiertos y labrados los terrenos. Como mismo el sistema de tumba y quema garantizaba los más elevados rendimientos en las plantaciones cañeras, la expansión de los potreros pudo aprovechar la abundante materia orgánica para tener pastos con mayor poder nutritivo. Los bosques no desaparecieron del todo de los potreros, pero su relevancia fue cada vez menor para garantizar la alimentación y resguardo del ganado. Acerca de estos cambios, explica Monteverde (1856, p. 43-44):

Los montes, que sin embargo de ser lo mejor en terrenos de cada fundo, no servían antes a sus ganados sino de simple abrigo contra los fríos del invierno y para suplirles con sus bejucos y las hojas de algunos árboles (...) estos montes, antes casi inútiles, abiertos y cultivados después en potreros, no solo aumentaron el área del criadero de la Hacienda, o sea la extensión de pastos de cada una, sino que siendo sus producciones mucho más alimenticias que las espontáneas de las superficies de antiguo abiertas y cada año más agotadas, endurecidas y estériles, permitieron aumentar las crianzas y estas fueron mejores.

Otro residente en Puerto Príncipe, Gaspar Betancourt Cisneros, "El Lugareño”, expresa que lo más perjudicial para la industria y la población de esta región es la rutina "de criar vacas en comunidad, o, mejor dicho, de que las críe la Naturaleza, ocupando una extensión inmensa con los mismos animales que pudieran criarse en pocas caballerías". Para demostrarlo, comparaba el valor aproximado de una hacienda de 1.600 caballerías y el de esta misma dividida en 80 potreros de alrededor de 20 caballerías. De esta forma, los nuevos potreros llegaban a valer diez veces más de lo que el hato entero previo a la subdivisión. El Lugareño pedía a sus coterráneos que se reconociera con franqueza que gracias a esta transformación, "la carne es mucho más gorda y sana, la manteca más barata, los quesos se perfeccionan cada año, y si no se come mantequilla fresca es porque nadie se ha puesto a especular con ese ramo de la industria". Tales progresos se debían por entero "al sistema de división de haciendas o de potreros. A medida que el antiguo sistema de crianza se enlaza con el moderno de agricultura, aquel se perfecciona por éste”. (Betancourt, 1950 [1838], pp. 30-38, 143-163)

Esa complementariedad fue vista asimismo como un modo de evitar los estragos a largo plazo del sistema de tumba y quema de bosques. Monteverde (1856), para quien la regeneración de la ganadería estaba unida a la prosperidad del país, cuestionó que se considerase como utilidad lo que en realidad no lo era. Introdujo así observaciones que añadían a las valoraciones económicas convencionales criterios ecológicos, al censurar que en los gastos se omitieran la pérdida progresiva de la fertilidad de los terrenos de las haciendas -por insolaciones, vientos y lluvias torrenciales-, la invasión de plantas "más duras y menos útiles que las que poblaban las sabanas" y el deterioro del ganado; los edificios y "caducidad” de los negros esclavizados. El naturalista español La Sagra (1862, pp. 75-76) indicaba al respecto que la doctrina de Monteverde introducía en la contabilidad rural "la luz que necesitaba".

Otra opinión valiosa sobre la ganadería en los territorios del centro oriente cubano la ofrece el naturalista español Miguel Rodríguez Ferrer, quien residió varios años en la ciudad de Puerto Príncipe y fue hacendado ganadero en su zona. Varios de sus escritos se hacen eco de la problemática ganadera y sus contrastes con el occidente azucarero, sin el sesgo de evaluar la situación de la isla a partir de la realidad de la capital. Poco antes de su partida de regreso a España, presentó en un cabildo extraordinario de Puerto Príncipe del 24 de febrero de 1861 un informe sobre el proyecto de un ferrocarril entre la ciudad de Puerto Príncipe y el puerto de Santa Cruz del Sur (en nombre de una comisión a su cargo). La nueva línea sería complemento de la ya existente entre la primera ciudad y Nuevitas, cuya importancia fue vital para que la capital de la jurisdicción, distante de 
ambas costas, dejara de ser el pueblo "más pastoril y estacionario de toda la isla". El nuevo recorrido atravesaría terrenos mucho más fértiles, que luego podían despertar la avidez de los grandes capitales del occidente en busca de esos terrenos vírgenes "por su especial sistema de ir siempre tumbando el bosque para sembrar sobre sus primitivos jugos". Este sistema, lamenta -a pesar de sus perjuicios-, "ha de continuar practicándose mientras no haya una población de tres millones de almas que lo modifique" (Rodríguez, 1861, p. 2).

No obstante, el naturalista se opuso a que Puerto Príncipe acabara con sus "rasgos preponderantes de criadora" y que por esto abandonara sus productivos potreros para "no ser más que ingeniera". Si bien habría podido afrontarse el cultivo de la caña por los mayores capitales, no debía la jurisdicción "perder por completo sus antiguos elementos, sino regenerarlos ilustradamente". A medida que otras zonas iban trocando sus potreros por cañaverales, sin dejar de necesitar bueyes y carnes, más se podrían aumentar las crías y la ceba de ganado, de modo que el centro debía proveer la isla entera, "como lo hace Extremadura a muchas provincias de España". Mientras más cultivos y más distintas industrias tuviera un país, "más al abrigo se ponía de las catástrofes físicas y de las crisis comerciales" que lo amenazaban cuando prevalecía un solo producto. De ese modo, según advierte Rodríguez Ferrer (1861, p.7), “si todos son ganaderos, el país no progresará: si todos azucareros, las crisis todo lo paralizan. En el equilibrio de estas fuerzas de producción está por tanto el bien y la prosperidad".

El hecho de que la ganadería se mantuviera como la actividad económica fundamental de buena parte de los territorios del centro y el oriente llevó a que en esos territorios se prestara mayor atención al perfeccionamiento de la cría de animales en los potreros. Dos vías para lograr ese objetivo fueron la celebración de ferias ganaderas y la introducción de nuevas razas de ganado vacuno para su cruzamiento con el criollo. En 1843 se efectuó la primera de esas ferias en la ciudad de Puerto Príncipe, cuya primera etapa se extendió hasta 1847. Luego se reanudaron en 1856 en un nuevo espacio mejor acondicionado en el Casino Campestre (Monteverde, 1858) y se celebraron hasta 1868. También se efectuaron ferias de ganado en otras ciudades centro-orientales como Bayamo y Remedios.

A partir de 1846 llegaron a Cuba los primeros ejemplares de las razas Durham, Ayrshire, Hereford y Devon, importados desde Estados Unidos por hacendados de Puerto Príncipe y otras jurisdicciones ganaderas, con el fin de formar animales mestizos más productivos (Monteverde, 2012 [1861]). Esta práctica fue criticada desde La Habana por autores, como el conde de Pozos Dulces, quienes eran partidarios de la mejora de la raza del país mediante la selección, en lugar de recurrir al cruzamiento, lo que originó un amplio debate entre los partidarios de una u otra estrategia. Pero con independencia de las dificultades en la aclimatación del ganado, los hacendados principeños y los de otras zonas ganaderas, como Bayamo y Sancti Spiritus, se atribuyeron éxitos en los cruces de animales importados y criollos, como se puede apreciar en diversas fuentes. Arteaga (1864, p. 31), destacaba que en los programas de las ferias ganaderas se mostraban ya animales con una masa corporal total del orden de 90 a 130 arrobas $(1.022$ y $1.476 \mathrm{Kg})$, pesos que "eran desconocidos o enteramente fenomenales, antes de nuestro siglo".

De igual manera, la siembra de nuevos pastos artificiales tuvo una mayor incidencia en las zonas ganaderas del país, como se vio antes. Los más extendidos fueron la yerba de guinea y la yerba del Paral, del Brasil o del Pará (o Paraná). La primera, originaria de África ecuatorial, ya estaba presente en Cuba a inicios del siglo XIX. Al parecer arribó procedente de Jamaica u otras islas caribeñas primero a las zonas del centro-oriente cubano (Parsons, 1972). La segunda, también africana, llegó más tarde en el mismo siglo desde Sudamérica y ya estaba bien establecida en los potreros camagüeyanos hacia 1850. En su diccionario botánico de nombres vulgares cubanos, cuya primera edición es de 1928, Roig (1965, pp. 959-960 y 970-971) escribió que ambas gramíneas eran los mejores pastos artificiales en las zonas ganaderas y los preferidos en Camagüey y Oriente.

Todos esos esfuerzos, sin embargo, se veían limitados por poderosos factores ya mencionados, como el creciente reemplazo de fuerza de tracción animal por el avance de la mecanización de los ingenios y las líneas de ferrocarril en el occidente plantacionista. A esto se sumaba la masiva importación de productos de origen animal para alimentar las dotaciones de esclavos y abastecer los principales mercados de consumo de la isla. 
Esta situación llego a un extremo con la importación de ganado vacuno en pie desde Centroamérica y desde el Sur de los Estados Unidos con destino a su sacrificio en los mataderos de La Habana, en detrimento de los intereses ganaderos de la isla. (Funes, 2012c; Payne, 2007; Otto, 1984)

Los empeños por la mejora de la ganadería y los potreros quedaron aplazados por el estallido de la Guerra de los Diez Años en 1868, cuyo escenario fundamental serían las principales regiones ganaderas centroorientales. La contienda por la independencia debió tener una gran incidencia, aún por determinar, sobre la masa vacuna del país. Aunque los censos coloniales hasta 1862 no llegan a superar el millón y medio de cabezas, algunas estimaciones indican que la cifra real pudo ser mucho mayor. Por ejemplo, Rodríguez Ferrer (1876, p. 806) afirmó que el número de cabezas de ganado antes del inicio de la guerra pasaba de tres millones, sobre todo en las haciendas y bosques de la mitad oriental. Con la guerra, el abandono de los potreros y sitios de crianza en territorios afectados por el conflicto se combinó con el hecho de que los animales se convirtieron en un elemento estratégico para la alimentación de los contendientes todo lo cual produjo un fuerte decremento en el volumen del ganado.

La reconstrucción de los territorios que fueron escenario de la primera guerra por la independencia se haría en algunas zonas a partir de la erección de los nuevos ingenios centrales, favorecidos por la abundancia de territorios boscosos y la posibilidad de emprender proyectos de colonización agrícola. No obstante, buena parte de la reactivación económica de las zonas devastadas por la guerra dependió del resurgimiento de los potreros y de la ganadería. Por ejemplo, un informe de 1886 sobre la jurisdicción de Sancti Spíritus daba cuenta de que la rehabilitación de los valiosos potreros de yerba de guinea se había mostrado más activa que en los demás ramos de la riqueza pública. Gran parte de ingenios demolidos fue convertida en potreros, en su totalidad o en una porción de sus tierras, a la vez que surgían numerosos potreros independientes de guinea sin casas y sin cercas. ${ }^{13}$

A fin de contribuir a la reconstrucción de las zonas ganaderas se concedieron facilidades para la importación libre de derecho de animales con destino a la crianza desde puertos de Estados Unidos, Jamaica, México, Colombia, Centroamérica y Puerto Rico, entre otros. En vísperas de la guerra de 1895 aparecen estadísticas que reflejan una suma superior a los 2,5 millones de cabezas de ganado vacuno en toda Cuba. Es posible que las grandes existencias de ganado en los potreros de las principales zonas criadoras hacia mediados de la década de 1890 tuvieran que ver aún con la persistente competencia de la importación de carnes y producciones de origen animal desde el extranjero. Entre estas sobresalían el tasajo de Argentina y las carnes en conserva, manteca, tocino u otras producciones procedentes de los mataderos de Estados Unidos. La entrada de las carnes extranjeras, a las que se concedían amplias ventajas en el mercado cubano para favorecer a productos españoles como la harina, o a los cultivos comerciales de la colonia como el azúcar y el tabaco, contrastaba con las elevadas cargas impositivas que se mantenían sobre la ganadería. Se decía entonces que entre dos terceras partes o tres cuartas partes de los presupuestos municipales se cubrían con impuestos a la ganadería y a sus industrias derivadas. En una airada protesta sobre este tema en el año 1894, la Asociación de Ganaderos de Sancti Spíritus se expresaba así acerca de la importación libre de productos de origen animal:

facilidades que se convierten en liberalidades que nos lastiman, que nos ofenden porque envuelven un soberano desprecio para los poseedores de la tercera, sino la segunda, de las fuentes de bienestar de los habitantes de esta infortunada Antilla, de la riqueza que ocupa mayor extensión de nuestro territorio, de la industria que alimenta a un número mayor de su población durante todo el año, y a la cual se refugian los trabajadores cuando pasan las tareas de las otras dos (Memoria que la Asociación de Propietarios de las Riqueza Rústica y Pecuaria de Sancti Spiritus dedica al Sr. D. José A del Cueto Pazos, Diputado a Cortes por este Distrito. Imprenta de Canto, Sancti Spíritus, 1894, 29)

\section{BREVE CONCLUSIÓN}

La historiografía sobre Cuba en el periodo colonial presta poca atención a la importancia de la ganadería en el panorama económico, social y político del país. El rey azúcar ha acaparado casi toda la atención, seguido 
de lejos por otros cultivos comerciales. En el siglo XIX entraron en escena las nuevas tecnologías de la era del vapor, que convirtieron a la isla en uno de los núcleos fundamentales de lo que hoy se conoce como la "segunda esclavitud", para designar el nuevo auge de este sistema de trabajo forzado en distintos territorios americanos en el contexto del avance de la primera revolución industrial (Tomich, 2004; Piqueras, 2016). Ese rutilante salto a la modernidad, de trapiches movidos por máquinas de vapor, ferrocarriles, evaporadores al vacío y centrífugas contribuye aún más a que se pase por alto el todavía significativo papel de los animales como fuente de energía y alimento, o de estatus social, y, por tanto a eclipsar su profunda incidencia en una sociedad que se encontraba en los inicios de la transición de una economía orgánica avanzada a una economía basada en la agricultura industrializada y los combustibles fósiles.

Así como Moreno Fraginals describió al ingenio - unidad productiva de la plantación esclavista azucareracomo el complejo económico social cubano del azúcar, tal vez podríamos decir que el potrero constituyó el complejo económico social de la ganadería cubana durante el siglo XIX. Estudiar su funcionamiento resulta vital para tener una visión más completa de las áreas dominadas por las plantaciones, y, sobre todo, de aquellas que quedaban fuera de sus márgenes (zonas de fronteras que eran ocupadas por la marcha hacia el este del azúcar, y los aún extensos territorios en los que predominaba la ganadería en sus formas más tradicionales o que se iban transformando con la aparición de los potreros). También resulta útil para comprender las complementariedades y conflictos entre ambas zonas, las denominadas Cuba A y Cuba B en la conceptualización citada de Juan Pérez de la Riva.

A partir de los principales autores que se dedicaron al tema de la ganadería en ese siglo, se ha hecho referencia en este trabajo a las características generales de la evolución de los potreros cubanos en el siglo XIX, su expansión territorial, sus variaciones en las áreas dominadas por las plantaciones esclavistas y aquellas que estaban fuera de su influencia directa. También se avanzó sobre algunos elementos referidos a las innovaciones en las formas de manejo, la introducción de nuevas razas de animales, la siembra de pastos artificiales para mejorar la alimentación, las ferias ganaderas o los llamados a una integración entre la agricultura y la ganadería, junto a la creación de reservas forestales en los nuevos potreros. Resulta notorio que muchos de los autores hayan visto en estas unidades una esperanza para la necesaria transformación del sistema agrícola cubano -basado en el monocultivo y en el trabajo esclavo-, como es el caso de Juan Bautista Jiménez con su expresivo libro El potrero paraiso, de 1888. Este tipo de argumento invita a tener más en cuenta el papel de los animales en la historiografía sobre Cuba, que hasta el presente se ha centrado casi siempre en unas pocas plantas identificadas como la fuente de la riqueza del país.

Aunque no se cumplieran las expectativas más optimistas, resulta evidente que la formación de potreros en toda la isla representó un cambio fundamental en las formas de manejo de la ganadería y en los paisajes insulares, lo cual debe ser estudiado con mas atención. La transición desde los sistemas de crianza libre tradicionales hacia unidades cercadas se desenvolvió en plazos y en formas diferentes en los territorios dominados por las plantaciones azucareras y en los que aún tenían la ganadería como actividad económica fundamental. Fue en estos últimos donde los esfuerzos por la mejora del potrero tuvieron mejores resultados, gracias a la introducción de nuevas razas bovinas europeas para su cruce con el ganado criollo, la siembra de gramíneas africanas para formar pastizales más nutritivos y la celebración de ferias ganaderas para estimular el espíritu de competencia entre los productores. Sin embargo, se ha visto que esos esfuerzos tropezaron siempre con enormes obstáculos, como la temprana llegada de las tecnologías de la era del vapor y la elevada importación de alimentos u otros productos de origen animal.

Todos estos temas serán estudiados con más profundidad en el futuro, junto a otros que apenas se mencionan aquí, por cuestiones de espacio, como la presencia de la esclavitud en la ganadería, el consumo local de productos de origen animal o los sectores sociales característicos del mundo ganadero. Estudiar el potrero cubano del siglo XIX implica acercarnos a la formación del campesinado cubano, llamado guajiro desde ese mismo siglo, que salvo en el caso del cultivo del tabaco, parece haber sido entonces más ganadero que agricultor. Así se puede ver en muchas de las descripciones costumbristas sobre este personaje campestre 
por excelencia. Esa visión sobre la zona ganadera, como reducto de la patria criolla frente al empuje de la modernización esclavista e industrial, fue descrita en los siguientes términos por José Quintín Suzarte, a la altura de 1881:

Hoy el tipo legítimo del guajiro no se encuentra sino en algunos puntos del interior de la isla, donde no imperan aún el ferrocarril, el telégrafo, el teléfono y las demás gollerías de la civilización. En el departamento Occidental ya no existe el guajiro que cantaron Domingo Delmonte, Ramón de Palma, Ramón Vélez Herrera y otros poetas notables. Hay que ir a algunos lugares del Centro y el Oriente para dar con él.

La contraposición entre ganadería y civilización es quizá uno de los preconceptos más arraigados en los discursos modernizadores en Latinoamérica desde el siglo XIX. (Duncan y Markoff, 1978) Sin embargo, la ganadería y la relación con los animales resultó ser mucho más dinámica y cambiante de lo que se podría pensar dentro de una historiografía tan permeada por una visión lineal y ascendente del progreso. Analizar el potrero y sus implicaciones económicas, sociales, políticas y ambientales resulta fundamental para profundizar en las implicaciones de la intensificación ganadera a largo plazo, o sobre temas como el consumo de proteínas de origen animal. Y también para establecer las relaciones entre la posesión de tierras, cabezas de ganado y poder político en la continua apertura de nuevas fronteras agrícolas a partir de la conversión de los bosques en potreros, historia que tiene raíces muy antiguas y que sigue viva en muchas zonas intrincadas de la frontera boscosa o agrícola latinoamericana.

\section{ReFERENCIAS}

Amaral, S. (1998). The Rise of Capitalism on the Pampas. The Estancias of Buenos Aires, 1785-1870. Cambridge: University of Cambridge Press.

Arango y Parreño, F. de (2006). Obras, vol. II. La Habana: Ediciones Imagen Contemporánea.

Arteaga, J. (1864). Estudios Agricolas. Primera serie. Estudios sobre el ganado vacuno. Puerto Príncipe: Imprenta El Fanal.

Bachiller y Morales, A. (1846). Memoria sobre el número y valor de los ganados de la Isla. Obstáculos que se oponen a su producto, y medios de fomentar su consumo y el de nuestras pesquerías. Memorias de la Sociedad Económica de La Habana, vol. 21, núm., 2, 345-360.

Balboa, I. (1991). La ganadería en Cuba entre 1827 y 1862. Nuestra Historia, 1, 21-34.

Balboa, I. (2013). De los dominios del Rey al imperio de la propiedad privada: estructura y tenencia de la tierra en Cuba (siglos XVI-XIX). Madrid: CSIC.

Bell, S. (1998). Campanha Gaúcha. A Brazilian Ranching System, 1850-1920. Stanford: Stanford University Press.

Betancourt, G. (1950). Escenas Cotidianas. La Habana: Ministerio de Educación.

Cabrera, G. (2018). Ignacio Zarragoitía y Jáuregui y la defensa de la Cuba no azucarera. Jagwa Pana, 17(3), http://d x.doi.org/10.21676/16574923

Díaz del Olmo, F., Cámara, R., y Batlle, J. R. (2002). Hatos caribeños y dehesas andaluzas. Paisaje y estructura parcelaria. En J. R. Navarro (Coord.), Cuba y Andalucía entre las dos orillas (pp. 303-333). Sevilla: Junta de Andalucía, CSIC.

Duncan, S. R., y Markoff, J. (1978). Civilization and Barbarism: Cattle Frontiers in Latin America. Comparative Studies in Society and History, 20(4), 587-620.

Edelman, M. (1992). The Logic of The Latifundio: The Large States of Northwestern Costa Rica Since the Late Nineteenth Century. Stanford: Stanford University Press.

Escalada y Gil, M. (1851). Memoria sobre el comercio y consumo de ganados en el rastro y carnicerías de La Habana, por D. Miguel Escalada y Gil. MSEH, núm. 26, vol. 2, 313-337. 
Escalada y Gil, M. (1858). Carta de Miguel Escalada, vecino del pueblo de Bainoa. El Dr. Manuel González del Valle, sobre el estado de la educación primaria en aquel partido..., 10 de agosto de 1838. MSEH, núm. 33, vol. 1, 198-215.

Frías, F. de (1849). Memoria sobre la industria pecuaria en la Isla de Cuba. La Habana: Imprenta del Diario de la Marina. Frías, J. J. de (1844). Ensayo sobre la cría de ganados en la Isla de Cuba. La Habana: Oficina del Faro Industrial.

Funes, R. (2008). From Rainforest to Cane Field in Cuba. An Environmental History since 1492. Chapel Hill: UNC Press.

Funes, R. (2012 a). Especialización azucarera y crisis de la ganadería en Cuba, 1790-1868. Historia Agraria, 57, 105-134.

Funes, R. (2012 b). Cultura ganadera en la historia de Cuba. Una aproximación, Catauro. Revista Cubana de Antropología, 13(25), 6-28.

Funes, R. (2012c). Protesta desoída: Puerto Príncipe frente a la importación de ganado en La Habana desde 1859. En E. Cento (Comp.). Cuadernos de Historia Principeña, 10 (pp. 54-72). Camagüey: Editorial Ácana.

Funes, R. (2016). Rise and fall of Dairy Cows in Socialist Cuba. Global Environment, 9(2), 342-375.

Ghorbal, K. (2006). ¿De la teoría a la práctica? Lógica antiazucarera y colonización blanca en el pensamiento de Gaspar Betancourt Cisneros. En E. Cento (Ed), Cuadernos de Historia Principeña (pp. 57-79). Camagüey: Editorial Ácana.

González, T. (2008). Rasgos de la ganadería en Camagüey desde la fundación de la villa hasta 1868. En E. Cento (Comp.), Cuadernos de Historia Principeña, 7 (pp. 35-48). Camagüey: Editorial Ácana.

Higman, B. W. (1989). The Internal Economy of Jamaican Pens, 1760-1890. Social and Economic Studies, 38(1), 61-86. Tomado de http://www.jstor.org/stable/27864852

Jiménez, J. B. (1888). El potrero Paraíso. Santa Clara: Imprenta El Trabajo.

López, E. (2015). Tabaco. Mito y esclavos. Apuntes cubanos de historia agraria, La Habana: Editorial de Ciencias Sociales Marrero, L. (1984). Cuba. Economía y Sociedad. Madrid: Ed. Playor, t. 10.

Monteverde, M.(1856). Estudios prácticos de las condiciones económicas de la industria pecuaria en el distrito de Puerto Principe. Puerto Príncipe: Imprenta El Fanal.

Monteverde, M.(1858). Memoria de la Feria y exposición de ganados y productos agrícolas y pecuarios celebrados en la ciudad de Puerto Principe del 1 al 13 de septiembre de 1857. Puerto Príncipe: Imprenta del Fanal.

Monteverde, M.(2012) [1861]. Cuestión ganadera. Informe, Catauro. Revista Cubana de Antropología, 13(25), 107-124.

Moreno, M. (1978) [1964]. El ingenio. Complejo económico-social cubano del azúcar. La Habana: Editorial de Ciencias Sociales.

Morgan, P. D. (1995). Slaves and Livestock in Eighteenth-Century Jamaica: Vineyard Pen, 1750-1751. The William and Mary Quarterly, 52(1), 47-76. doi: https://10.2307/2946887

Nova, J. (2008). Haciendas ganaderas en Holguin, 1545-1867. Holguín: Ediciones Holguín.

Noticias estadísticas de la Isla de Cuba en 1862... (1864). La Habana: Imp del Gobierno, Capitanía General y Real Hacienda.

Ortiz, F. (1940). Contrapunteo cubano del tabaco y del azúcar. La Habana: Jesús Montero Editores.

Otto, J. S. (1984). Florida's Cattle-Ranching Frontier: Hillsborough County (1860). The Florida Historical Quarterly, 63(1), 71-83.

Parsons, J. (1972). Spread of African Pasture Grasses to the American Tropics. Journal of Range Management, 25(1), 12-17. doi: https://10.2307/3896654

Payne, E. (2007). El Puerto de Trujillo. Un viaje hacia su melancólico abandono. Tegucigalpa: Editorial Guaymuras.

Pérez de la Riva, F. (1944). El café, historia de su cultivo y explotación en Cuba. La Habana: Jesús Montero Editores.

Pérez de la Riva, J. (2004) [1968]. Una isla con dos historias. En La conquista del espacio cubano (pp. 189-206). La Habana, Fundación Fernando Ortiz. 
Reinaldo Funes Monzote. “Un arcoíris en medio de la tempestad”. Visiones del potrero Cubano en el...

Pichardo, E. (1985) [1862]. Diccionario provincial casi-razonado de vozes (sic) cubanas. La Habana: Editorial de Ciencias Sociales.

Piqueras, J. A. (1999). El azúcar en Cuba y las fuentes para su estudio. América Latina en la historia económica. Boletín de fuentes, 6(11), 35-47.

Piqueras, J. A. (Coord.) (2016). Esclavitudy capitalismo histórico en el siglo XIX. Brasil, Cuba y Estados Unidos. Santiago de Cuba: Editorial Caribe.

Rodríguez Ferrer, M. (1876). Naturaleza y Civilización de la Grandiosa Isla de Cuba. Madrid: Imprenta de J. Noguera, $2 \mathrm{t}$.

Rodríguez Ferrer, M. (1861). Dictamen que en el cabildo extraordinario de 24 de febrero de 1861 celebrado en la ciudad de Puerto Principe presentó y leyó D. Miguel Rodríguez Ferrer... sobre el nuevo ferrocarril del camino de esta ciudad al puerto de Santa Cruz. Puerto Príncipe: Imprenta del Fanal.

Rivero, J. (1964). Tabaco. Su historia en Cuba. La Habana: Academia de Ciencias de Cuba.

Roig, J. T. (1965). Diccionario botánico de nombres vulgares cubanos. La Habana: Editora del Consejo Nacional de Universidades.

Sábato, H. (1989). Capitalismo y ganadería en Buenos Aires. La fiebre del lanar, 1850-1890. Buenos Aires: Editorial Sudamericana.

Sagra, R. de la (1862). Cuba en 1860. O sea cuadro de sus adelantos en la población, la agricultura, el comercio y las rentas públicas. París: Librería de L. Hachette y Cía.

Serrano, F. de P. (1847). La isla de Cuba actual. Agricultura. Crianza de ganados. MSEH, 24, 113-120, 165-174, 224-234.

Sesto, C. (2005). Historia del capitalismo agrario pampeano, t. 2. La vanguardia ganadera bonaerense 1856-1900. Buenos Aires: Siglo XXI de Argentina.

Shepherd, V. A. (1991). Livestock and Sugar: Aspects of Jamaica's Agricultural Development from the Late Seventeenth to the Early Nineteenth Century. The Historical Journal, 34(3), 627-643. Extraído de http://ww w.jstor.org/stable/2639565

Shepherd, V. A. (2009). Livestock, Sugar and Slavery. Contested Terrain in Colonial Jamaica. Kingston: Ian Randle Publishers.

Slatta, R. (1997). Comparing Cowboys and Frontiers. Norman: University of Oklahoma Press.

Sluyter, A. (2012). Black Ranching Frontiers: African Cattle Herders of the Atlantic World, 1500-1900. New Haven: Yale University Press.

Stubbs, J. (1985). Tobacco on the Periphery: A Case Study in Cuban Labor History, 1860-1958. Londres: Cambridge University Press.

Suzarte, J. Q. (2009) [1881]. Los Guajiros. En Tipos y costumbres de la isla de Cuba... Obra ilustrada por D. V. P. Landaluze (pp. 59-64). La Habana: Biblioteca Nacional de Cuba José Martí.

Tomich, D. (2004). Through the Prism of Slavery: Labor, Capital, and the World Economy. Lanham, MD: Rowman and Littlefield.

Torre, J. M. de la (1849). Comunicaciones dirigidas a la Real Junta de Fomento, MSEH, Serie 2, 6, 293-302.

Van Ausdal, S. (2009). Potreros, ganancias y poder. Una historia ambiental de la ganadería en Colombia, 1850-1950. Historia Critica, Edición Especial, noviembre, 126-149.

Van Ausdal, S., y R. W. Wilcox (2018). Hoofprint: Cattle Ranching and Landscape, Soluri, John, Claudia Leal y José Augusto Padua (Eds.). En A Living Past. Environmental Histories of Modern Latin America (pp. 183-204). New York: Berghahn.

Wilcox, R. W. (2017). Cattle in the Backlands: Mato Grosso and the Evolution of Ranching in Brazilian Tropics. Austin: University of Texas Press.

Zamora Coronado, J. M. (1840). Registro de legislación Ultramarina. La Habana: Imprenta del Gobierno y Capitanía General. 


\section{Notas}

1 El potrero latinoamericano se asemejaría más bien a las denominadas dehesas de la geografía hispana, definidas como un espacio de tierra acotada y destinada a pastos. (Díaz del Olmo, Cámara y Batlle, 2002)

2 “Agricultura. Cartilla rústica. Diálogo entre un Labrador y su hijo”, Memorias de la Sociedad Económica de La Habana, 1841, t. XII, 245-258.

3 Lo que se llama millo en Cuba son en realidad sorgos, variedades del Sorghum vulgare Pers. Afirma que en las cercanías de La Habana se sembraba mucho millo para maloja o forraje. Entre los híbridos más comunes en Cuba menciona el millo blanco y el millo negro.

4 Los ingenios aparecen con 172,671. Los potreros le siguen con 31,514, pero si se suman los 6,220 que trabajaban en las haciendas, esto representa un total de 37,734 esclavos empleados directamente en actividades ganaderas (el $13 \%$ de los esclavos en labores agrícolas). Otra cantidad imposible de precisar también podía estar dedicada al manejo de animales en ingenios, cafetales, sitios de labor, vegas, estancias u otras fincas. En los cafetales aparecían 25.942 esclavos y en las vegas 17.675 esclavos, que representaban respectivamente el $8,9 \%$ y el $5,9 \%$ en fincas.

5 "Documentos históricos de Cuba. Colección de Manuel Villanova, XXIV. Bando del marqués de la Torre. Sobre que no se reduzcan a potreros las estancias y sitios de labor”. Revista Cubana, t. X, 1889, 454-457.

6 Archivo General de Indias (AGI), Santo Domingo, 1606. Expediente sobre el abasto de carne fresca en aquella ciudad. Dictamen de Baltasar de Sotolongo, ff. 167-187.

7 Sistema creado por la Marina Real Española en Cuba en la segunda mitad del siglo XVIII para la extracción de maderas. Ver Funes, 2008, pp. 59-82.

8 AGI, Cuba 1694. Informe de Pedro Acevedo al presidente y demás señores de la Junta de Maderas, La Habana, noviembre 22 de 1794.

9 "Informe al alto Ministerio del año de 1797 con las dudas que opuso el señor don José Pablo Valiente al destructor proyecto de una medición general de haciendas, para descubrir realengos”.

10 Relación numérica de los ingenios, cafetales, vegas de tabaco, potreros, estancias y sitios de labor distribuidos por provincias y formada con vista de los estados publicados por la Gaceta Oficial correspondiente al 20 de marzo de 1877, Revista de Agricultura, $1(5), 1879,126-130$.

11 “Agricultura. Cartilla rústica. Diálogo de un Labrador y su hijo”, Memorias de la Sociedad Económica de La Habana, 1841 , 245.

12 Pichardo, 1985, 483-484: "Peso de posesión: Moneda imaginaria, valor o precio de los terrenos de una Hacienda comunera. Cuando estas se mercedaron, sus primeros poseedores les prefijaron un valor que vino a ser casi el generalmente adoptado de 4,000 pesos el Corral y por el equivocado concepto de doble área del Hato en 8,000 pesos. Estas cantidades se fraccionaban en porciones de 50, 125, 300, etc. Pesos de Tierra, equivalentes proporcionalmente a la extensión superficial del fundo; pero cuya fracción no se sabía ni puede saberse mientras no se practica la operación del deslinde y división del Corral o Hato... Si el Corral fuese completo, fácil sería calcular la equivalencia de los Pesos de tierra de cada uno en porciones y medidas determinadas... en Caballerías de tierra (como se usa) teniendo el Corral 421 caballerías 123 cordeles cuadrados y partidos por ellas los 4000 pesos, corresponden 9 1/2 pesos por Caballerías. Mas como son pocos los Corrales o hatos completos, las proporciones no son iguales..."

13 “La Reconstrucción de Sancti Spíritus”, en Revista de Agricultura, año 7, no. 1, enero de 1886, 65-69.

\section{BY-NC-SA}

